\title{
PECULIARITIES OF INDIVIDUAL INDICATORS OF COLLAGEN METABOLISM AND LEVEL OF MATRIX METALLOPROTEINASE-9 IN CASE OF GASTROESOPHAGEAL REFLUX DISEASE IN PATIENTS WITH SYNDROM OF UNDIFFERENTIATED CONNECTIVE TISSUE DYSPLASIA
}

\author{
Iryna Romash
}

Department of Propaedeutics of Internal Medicine, Ivano-Frankivsk National Medical University (IFNMU), Ivano-Frankivsk, Ukraine

\begin{abstract}
The objective of the research was to study the prevalence of phenotypic and visceral markers for the syndrome of UCTD in patients with gastroesophageal reflux disease (GERD) and the nature of changes individual indicators of collagen metabolism and level of matrix metalloproteinase-9 (MMP9).
\end{abstract}

Materials and methods. The study included 120 patients: 75 patients (Group II) GERD was on the background of UCTD, 45 (Group I ) - the patients with GERD. The control group consisted of 12 practically healthy persons, without signs of UCTD. The average age of the patients was $42.0 \pm 6.5$ years. Evaluations of UCTD's were performed accordingly to the criteria recommended by $\mathrm{M}$. Moska et al., A. Doria et al., T. I. Kadurina, L. M. Abbakumova in the modification of T. Milkovskaya-Dimitrova, and the degree of their expression on the scale of T. Y. Smolnova. Concentration of oxyproline (OP) in blood serum and daily portion of urine was determined by photocolorimetric method. Matrix metalloproteinase- 9 in serum was tested by immunoassay method.

Conclusions: In adults with GERD in the background of UCTD, arthralgia, Raynaud's phenomenon, reduced body mass, bone, articular and skin phenotypic signs correlating with the frequency and duration of GERD, and treatment tactics of such patients should take into account these changes.

Key words: gastroesophageal reflux disease, undifferentiated connective tissue dysplasia, visceral and phenotypic markers, oxyproline, matrix metalloproteinase-9.

Introduction. Undifferentiated connective tissue dysplasia (UCTD) is characterized by the signs reflecting the systemic autoimmune process which does 
not correspond to any accepted diagnostic criteria for diseases such as rheumatoid arthritis, Sjogren's syndrome, systemic scleroderma, polymyositis and dermatomyositis, systemic lupus erythematosus, and mixed connective tissue diseases (Doria A.,2005; Mosca M, et al.,2014; Ferri et al.,2016; Antunes M. et al., 2018). Also, at the moment, the UCTD is considered as a basis that identifies the features of the course of the associated pathology and the tendency to chronisation the latter, frequent relapses, determines the peculiarities of approaches to the treatment of such combined pathology and its effectiveness. The digestive system is the second by the highest level of collagenization after the cardiovascular system, changes in it are particularly often observed in case of UCTD (Nica A. E.,et al., 2016). It causes changes in the length and size of the digestive system and the esophagus first of all, which is likely to be due to its mesenchymal origin (Bodolay E., et al., 2003). At the same time, the manifestations and mechanisms of formation of comorbidity UCTD and GERD in adults have not been sufficiently studied.

The objective of the research was to study the prevalence of phenotypic and visceral markers for the syndrome of UCTD in patients with gastroesophageal reflux disease (GERD) and the nature of changes individual indicators of collagen metabolism and level of matrix metalloproteinase-9 (MMP-9).

Materials and methods. The study included 120 patients: 75 patients (Group II) - GERD was on the background of UCTD, 45 (Group I ) - the patients with GERD. The control group consisted of 12 practically healthy persons, without signs of UCTD. The average age of the patients was $42.0 \pm 6.5$ years.

In addition to traditional general clinical and general laboratory methods, all patients purposefully searched for phenotypic and visceral signs of UCTD syndrome according to the criteria recommended by M. Moska et al., A. Doria et al., T. I. Kadurina, L. M. Abbakumova in the modification of T. MilkovskayaDimitrova (Doria A.,2005; Mosca M, et al.,2014; Soleiko O. V.,2014; Antunes M. et al., 2018). We used T. Yu. Smolnova scale in order to assess the aggregate and severity of CTD clinical manifestations. We also determined the presence of signs of hypermobility of the joints according to the Baiton criterion on a point scale, where one point is the presence of pathological overgrowth in one joint on one side. If 4 to 9 points are detected, hypermobility is established. Concentration of 
oxyproline (OP) in blood serum and daily portion of urine was determined by photocolorimetric method. Matrix metalloproteinase- 9 in serum was tested by immunoassay method.

The study was approved by the Bioethics Committee of the Ivano-Frankivsk National Medical University, and conducted in accordance with the principles of the Declaration of Helsinki. Prior to the start of the study, all patients signed informed consent.

Results: Accordingly to the obtained data, in patients of Group II, the next signs of UCTD as the Raynaud's phenomenon are found in more than 2.1 times, arthralgia - in 6.4 times, dysphagia -in 1.9, periodic skin rashes -in 3.2 times, ulcers of the mucous membrane of the oral cavity - in 3.7, as among patients of Group I. It must be noted more frequent development of proximal muscular weakness in the patients of the Group I. At the same time, in $88.0 \%$ of patients of the II Group were revealed abnormalities in the development of internal organs, while in the patients of Group I - only in 6.6\%. Nephroptosis and kidney dystopia were found in $46.6 \%$ of patients with comorbidity and in $15.5 \%$ of patients with independent GERD. As for the patients of the Group II, there were abnormalities more often $(86,6 \%)$ in the development of gall bladder, while in the patients with GERD only in $11,1 \%$.

Analysis of transnasal daily monitoring of $\mathrm{pH}$ in the lower third of the esophagus in patients with GERD and when combined with UCTD showed that reflux with a $\mathrm{pH}<4$ was recorded in $26.6 \%$ of patients of the Group I, and their number was $57 \pm 8$ episodes, with a total duration of $67 \pm 3$ minutes, which is $4.6 \%$ of the total monitoring period. In $60.0 \%$ of patients in Group II the number of acid reflux was $79 \pm 6$ episodes, total duration $87 \pm 8$ minutes, $5.48 \%$. The mean De Meester was $23.01 \pm 2.24$ for the GERD patients and $31.08 \pm 2.4$ for the patients with the combination of GERD with UCTD $(p<0.05)$. An increase in the percentage of time with $\mathrm{pH}<4$ in the lower third of the esophagus in the standing and lying position was also found, respectively, in $12.3 \%$ and $7.4 \%$ of patients with combined pathology, whereas in GERD without concomitant pathology, $10.2 \%$ and $5.8 \%$, respectively. According to the results of correlation analysis, there is a direct relationship between the number of refluxes with $\mathrm{pH}<4$ lasting more than 5 minutes and the level of oxyproline (OP) in the daily portion of urine 
$(\mathrm{r}=0.66)$ and between the number of refluxes $\mathrm{pH}<4$ lasting more than 5 minutes and the level of OP in serum $(r=0.79)$

The level of OP in blood serum and in daily portion of urine in patients of Group I is not different from healthy ones, but is lower in 1.7 times compared with Group II. The content of OP in patients Group II was higher by 2.9 times compared with the control group, and compared to the Group I, it was in 3.89 times higher $(\mathrm{p}<0.05)$. Concentration of MMP-9 in patients Group I was higher in 1.9 times, and in Group II - in 2.4 times compared with the control group ( $p$ $<0.05)$. Since oxyproline plays an important role in the stabilization of the secondary structures of collagen, determining its content in serum and daily urine can be considered as a marker of the breakdown of connective tissue components. Increasing the level of MMP-9 is able to enhance the hydrolysis of type IV collagen and lead to cardiac sphincter deficiency, as evidenced by the direct correlation between the number and duration of reflux and connective tissue markers.

Conclusions: The obtained data indicated that the number of pathological GER was significantly higher in the setting of comorbidity. In adults with GERD in the background of UCTD, arthralgia, Raynaud's phenomenon, reduced body mass, bone, articular and skin phenotypic signs correlating with the frequency and duration of GERD, and treatment tactics of such patients should take into account these changes.

\section{References:}

Antunes M, Scirè CA, Talarico R. et al.(2018) Undifferentiated connective tissue disease: state of the art on clinical practice guidelines. $R M D$ Open,4:e000786. doi:10.1136/rmd open-2018-000786.

Corte TJ, Copley SJ, Desai SR, et al. (2012) Significance of connective tissue disease features in idiopathic interstitial pneumonia. Eur Respir J., 39(3):661-8. doi: 10.1183/09031936.00174910.

Ferri C, Manfredi A, Sebastiani M. et al. (2016) Interstitial pneumonia with autoimmune features and undifferentiated connective tissue disease: Our interdisciplinary rheumatology-pneumology experience, and review of 
the literature. Autoimmunity Reviews, 15 (1):61-70.

doi.:10.1016/j.autrev.2015.09.003.

Mosca M, Tani C, Vagnani S. et al. (2014) The diagnosis and classification of undifferentiated connective tissue diseases. J Autoimmun., 48-49, 50-2. doi: 10.1016/j.jaut.2014.01.019.

Nica A. E., Alexa L. M., Ionescu A. O. et al. (2016) Esophageal disorders in mixed connective tissue diseases. Journal of Medicine and Life, 9(2), 141.143. PubMed Central PMCID: PMC4863503.

Bodolay E., Csiki Z., Szekanecz Z., Caramanolis G. P. et al. (2003) Five-year follow-up of 665 Hungarian patients with undifferentiated connective tissue disease (UCTD) Clinical and experimental rheumatology., 003,21, №3, 313-320.

Doria A., Mosca M., Gambari P. F. et al.(2005) Defining unclassifiable connective tissue diseases: incomplete, undifferentiated, or both? The Journal of Rheumatology., 32(2), 213-215.

Soleiko O. V. N. A. Rykalo, I. P. Osypenko, L. P. Soleiko (2014) The syndrome of undifferentiated connective tissue dysplasia: from the concept of pathogenesis to the treatment strategy. Vinnytsia, 2014, $168 \mathrm{c}$.

Keywords: gastroesophageal reflux disease, undifferentiated connective tissue dysplasia, visceral and phenotypic markers, oxyproline, matrix metalloproteinase-9 